\title{
The role of the informer in user behaviour
}

\author{
F. Russo \& G. Chilà \\ Università degli Studi Mediterranea di Reggio Calabria, \\ DIMET, Dipartimento di Informatica, Matematica, \\ Elettronica e Trasporti, Italy
}

\begin{abstract}
In this paper a statistical analysis of stated behaviour in emergency conditions is proposed. The analyzed sample is extracted by people participating in a planning transport seminar in June 2011. The analysis is finalized to evaluate user behaviour in evacuation conditions in relation to formal transportation decisions and in respect of the type of informer and the kind of dangerous event. Obtained results show especially the importance of the informer.

Keywords: evacuation conditions, hypothetical scenarios.
\end{abstract}

\section{Introduction}

In the last few years, several scientific papers have focused on evacuation simulation in emergency conditions. The simulation of user behaviour during an evacuation is a very complex problem, as the behaviour depends on different factors, such as the kind and entity of the dangerous event; socio-economic characteristics of users; panic. Demand models specified and calibrated in ordinary conditions cannot be directly applied for several reasons $[1,2]$. The international literature relating to evacuation conditions proposes many studies which focus on the hurricane emergency case, by estimating demand models based on revealed preference (RP) surveys. These are inferred from observations of a decision maker's actual choices, in relation to real contexts.

In much of the literature, two users' decisions are simulated: whether to evacuate and when. These decisions are generally simulated through a statistical approach, using simple relationships such as averages, rates and distributions [3, 4]. A different way is to specify a model in which the analyst introduces a probabilistic approach and hypothesizes the user decision [5]. In relation to destination choice simulation, a disaggregate choice model for hurricane 
evacuation was developed with post-Hurricane Floyd survey data collected in South Carolina in 1999 [6]. Hasan et al. [7] present a mixed logit model of household hurricane evacuation behaviour using original data from Hurricane Ivan. Montz et al. [8] develop a model, using TRANSIMS software, based on traffic data recorded during the evacuation due to Hurricane Katrina in 2005.

Most literature papers focus on the hurricane emergency case and consider revealed preference (RP) surveys for demand model estimation. As RP data are not available for all dangerous events, such models cannot be directly applied to other dangerous events [9]. The prediction of user behaviour becomes essential. For this purpose, evacuation trials and stated preference (SP) surveys may be conducted.

To approach this problem, in previous works we proposed a system of models [1,9] based on data obtained during evacuation trials, which are considered as RP with laboratory effect. Calibrated models belong to the SICURO research project [1-10], which includes models simulating path choice for emergency vehicles [11-15]. Models which allow us to obtain network flows and then to evaluate the risk indicator are assignment models. In the following we consider the dynamic approach [16] and the general framework of equilibrium [17], in which all the different inputs and outputs of the problem are given. Starting from [17], specific assignment models for evacuation conditions are proposed in [18-21], and a travel time function for evacuation condition is proposed in [22].

In this work, we introduce hypothetical scenarios to analyze, in the absence of evacuation trials, the statistical behaviour of users in evacuation conditions from their statements.

In Russo and Chilà [23] a statistical analysis of stated behaviour in emergency conditions has been carried out, considering a sample of people belonging to an academic department and characterized by a high cultural level. Obtained results have pointed out the importance of the informer that determines different responses of users, given a particular kind of dangerous event. In this work we should verify this result by analyzing a sample of people participating in a transport planning seminar. We propose several hypothetical scenarios, which could be classified as SP scenarios, considering different dangerous situations, with delayed effects in time. To construct the SP experiment, based on the statements of respondents about their preferences, we have defined: choice context and alternative options; attributes for each alternative; type of requested preferences; that is, the choice (the respondent indicates which option to choose in that context).

Below we describe hypothetical scenarios proposed for the sample considered (section 2) and obtained results from statistical analysis of statements (section 3); we then draw our main conclusions (section 4).

\section{Description of hypothetical scenarios}

This section shows hypothetical scenarios proposed in an experiment conducted at Mediterranea University of Reggio Calabria, during a planning transport 
seminar at the Laboratory of Transport System Analysis (LAST), which took place in June 2011. We asked people in the lab to fill out an information sheet on their socio-economic characteristics.

The experiment was developed as described below. The analyst read aloud the description of nine hypothetical emergency scenarios, one scenario at a time. Each user in the sample then had to fill out a paper ballot with all information relating to a choice context, choosing from a range of alternative options.

We tried to carry out an analysis finalized to establish the importance of various factors in the choice [23], which are subdivided into two main classes of objectives:

- a first-level objective, to evaluate user behaviour in relation to the decision to evacuate or not, of toward evacuate and by which transport mode (the formal transportation decisions);

- a second-level objective, to evaluate user behaviour, in relation to the informer and to the kind of dangerous event.

Emergency scenarios are synthetically described in table 1.

Table 1: $\quad$ Scenario description for dangerous events with delayed effect in the time.

\begin{tabular}{|c|c|c|c|c|c|c|}
\hline Scenario & $\begin{array}{c}\text { Kind of } \\
\text { dangerous event }\end{array}$ & $\begin{array}{l}\text { Effect in } \\
\text { the space }\end{array}$ & Informer & $\begin{array}{c}\text { Place of } \\
\text { users during } \\
\text { dangerous } \\
\text { event }\end{array}$ & $\begin{array}{l}\text { Evacuation } \\
\text { time }\end{array}$ & $\begin{array}{l}\text { Destination } \\
\text { and transport } \\
\text { mode }\end{array}$ \\
\hline 1 & Anthropogenic & Punctiform & Stranger & $\begin{array}{c}\text { User's } \\
\text { workplace }\end{array}$ & Free & Separate \\
\hline 2 & Anthropogenic & Punctiform & $\begin{array}{l}\text { Department } \\
\text { head }\end{array}$ & $\begin{array}{c}\text { User's } \\
\text { workplace }\end{array}$ & Free & Separate \\
\hline 3 & Natural & Diffused & Mayor & $\begin{array}{c}\text { User's } \\
\text { workplace }\end{array}$ & Scheduled & Separate \\
\hline 3 bis & Natural & Diffused & $\begin{array}{c}\text { Faculty } \\
\text { headmaster }\end{array}$ & $\begin{array}{c}\text { User's } \\
\text { workplace }\end{array}$ & Scheduled & Separate \\
\hline 4 & Anthropogenic & Diffused & Stranger & $\begin{array}{c}\text { New } \\
\text { environment }\end{array}$ & Free & Separate \\
\hline 4 bis & Anthropogenic & Diffused & $\begin{array}{l}\text { Representative } \\
\text { of mayor }\end{array}$ & $\begin{array}{c}\text { New } \\
\text { environment }\end{array}$ & Free & Separate \\
\hline 4 ter & Anthropogenic & Diffused & Professor & $\begin{array}{c}\text { New } \\
\text { environment }\end{array}$ & Free & Separate \\
\hline 5 & Anthropogenic & Punctiform & Stranger & $\begin{array}{c}\text { User's } \\
\text { workplace }\end{array}$ & Free & Joint \\
\hline 6 & Anthropogenic & Punctiform & $\begin{array}{c}\text { Department } \\
\text { head }\end{array}$ & $\begin{array}{c}\text { User's } \\
\text { workplace }\end{array}$ & Free & Joint \\
\hline
\end{tabular}

Scenarios 1 and 2 are very similar: in both cases the same kind of emergency is proposed, the difference is the informer who communicates the state of emergency to potential stakeholders: while for scenario 1 the informer is a stranger, for scenario 2, it is the head of department. The objective is to determine whether, according to the reliability of the informer who broke the news, different behaviour may be found in users.

Scenario 3 is more complex: it includes the possibility that a stream running by the engineering school may flood, and a scheduled evacuation time for those 
involved. The objective is to test whether, in this case, the user is willing to follow precise directions provided by the system operator (in this case, the mayor of the city), or panic, choosing to leave the area affected by the emergency immediately. Scenario 3 bis is similar to scenario 3, but it is characterized by the faculty headmaster as informer.

Scenario 4 was constructed by considering an environment different from the LAST, within the university campus: the environment is the city centre, and the objective is to test any differences in behaviour under more critical traffic conditions, in an urban rather than a campus context. Scenario 4 bis and 4 ter are similar to scenario 4 , but the informer is a representative of the mayor in scenario 4 bis and a professor in scenario 4 ter.

Finally, scenarios 5 and 6 are similar to scenarios 1 and 2, but a different choice structure is proposed to sample users. The goal here is to determine whether the choice of mode and destination is jointly made or otherwise, in emergency conditions, compared to what usually happens in ordinary conditions (see fig. 1).
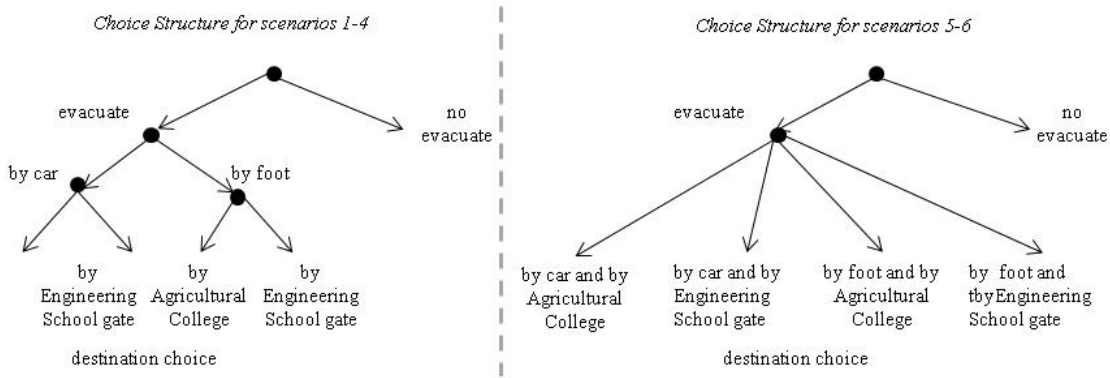

Figure 1: Choice structure for different scenarios.

For all scenarios, as well as checking the willingness of the user to evacuate, information on the choice of transport mode (car or foot) and destination (home or safe place indicated) is required.

Scenarios 1-3 and 5-6 are set in the university campus (fig. 2); scenarios 4, 4 bis, 4 ter are set downtown (fig. 3).

\section{Statistical analysis of responses}

The sample included 51 people, 22 women and 29 men, aged between 20 and 31 years. A percentage of $63 \%$ had participated in previous evacuation trials and the $61 \%$ of the total had, at least, sufficient knowledge of the risk field. The main characteristics of sample are reported in table 2. 


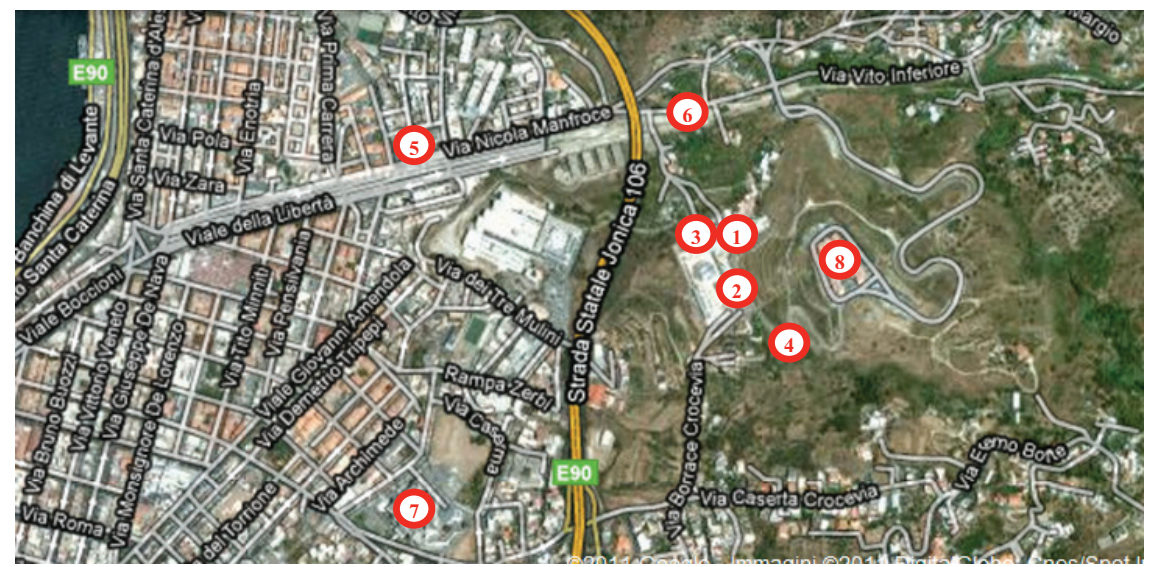

Legend: 1. LAST; 2. Engineering school car park; 3. Main engineering school exit; 4. Gate to the agricultural college; 5. Piazza San Brunello; 6. Annunziata torrent; 7. Palace of the Regional Council; 8. agricultural college.

Figure 2: View of the university campus.

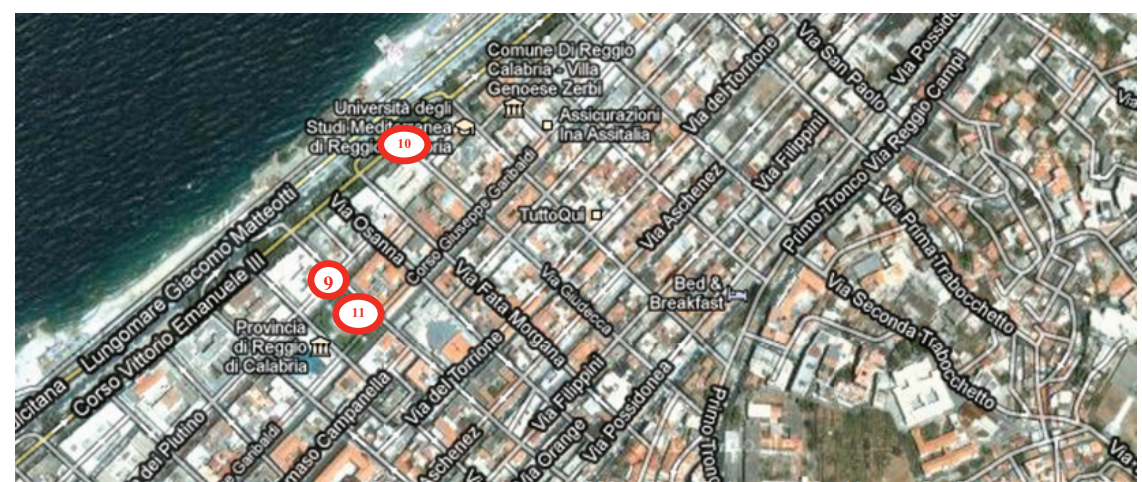

Legend: 9. Car park; 10. Tanker full of flammable liquid; 11. Town Hall, Hall of Lamps.

Figure 3: View of downtown.

\subsection{Scenario 1 results}

The scenario 1 results are expressed in percentages compared to the total number of users and show that:

- $88 \%$ of users leave the laboratory, while the remaining $12 \%$ do not trust the received information;

- $73 \%$ decide to move on foot, $16 \%$ choose to go to the campus car park and travel by car;

- $39 \%$ decide to continue to the agricultural college and $49 \%$ to leave by the engineering school gate;

- $65 \%$ then decide to go to the place designated by the stranger and $23 \%$ to reach their homes. 
Table 2: $\quad$ Sample description.

\begin{tabular}{cccc}
\hline Data & & Value & Percentage \\
\hline Sex & Male & 22 & $43 \%$ \\
& Female & 29 & $57 \%$ \\
\hline Age & Average & 21,02 & \\
\hline Professional status & Full Time Students & 49 & $96 \%$ \\
& Part Time Students & 2 & $4 \%$ \\
\hline Residence & Residents in Reggio Calabria & 29 & $57 \%$ \\
& Residents outside the province & 1 & $2 \%$ \\
& Residents inside the province & 21 & $41 \%$ \\
\hline Domicile & Domiciled in Reggio Calabria & 34 & $67 \%$ \\
\hline Socio-Economic data & Driving license owner & 50 & $98 \%$ \\
& Car owner & 35 & $69 \%$ \\
& Motorvehicle owner & 17 & $33 \%$ \\
\hline Knowledge of risk issues & Good & 4 & $8 \%$ \\
& Sufficient & 27 & $53 \%$ \\
& Poor & 20 & $39 \%$ \\
\hline Participation in evacuation & Yes & 32 & $63 \%$ \\
trials & No & 19 & $37 \%$ \\
\hline
\end{tabular}

\subsection{Scenario 2 results}

The scenario 2 results are expressed in percentages compared to the total number of users and show that:

- $96 \%$ of users leave the laboratory, while the remaining $4 \%$ do not trust the received information;

- $78 \%$ decide to move on foot, $20 \%$ choose to go out by car;

- $55 \%$ decide to continue to the agricultural college and $41 \%$ to leave by the engineering school gate;

- $80 \%$ then decide to go to the place designated by the informer and $16 \%$ to reach their homes.

\subsection{Scenario 1 vs. Scenario 2}

A comparison between the results obtained from scenarios 1 and 2 shows that:

- for scenario 2, the percentage of users who decide to leave the workplace increases by 8 percentage points: people perceive the information on emergency conditions from the director of the department as being more reliable;

- the percentage of users who choose to go out on foot, in comparison with scenario 1 , increases, and then users who leave in scenario 2, considering the received information more reliable, decide to get out on foot;

- the number of users who choose to go out via the agricultural college increases by 16 percentage points, as people consider the received information more reliable;

- as regards total users, for scenario 2, the number of users who decide to reach the place designated by the informer increased by 15 percentage points. 


\subsection{Scenario 3 results}

In comparison with scenarios 1 and 2, the dangerous event changes in scenario 3: even if both events have delayed effects in time, in scenarios 1 and 2 the kind of event is anthropogenic and related to the workplace of users; in scenario 3 the disaster is natural and concerns a wider area.

Scenario 3 results are expressed in percentages compared to the total number of users and show that:

- $45 \%$ of users leave the laboratory immediately and do not wait for the specified time of evacuation;

of those who leave immediately

- $31 \%$ decide to move on foot, while the remaining $14 \%$ choose to go to the campus car park and travel by car;

- $23 \%$ decide to continue to the agricultural college and $22 \%$ decide to leave by the engineering school gate;

- $33 \%$ of the total decide to get to the place designated by the mayor, while the remaining $12 \%$ reach their homes;

of those who wait for the specified time of evacuation ( $55 \%$ of the total)

- $53 \%$ of users leave the laboratory while $2 \%$ stay behind;

- $33 \%$ decide to move on foot, while the remaining $20 \%$ choose to go to the campus car park and travel by car;

- $32 \%$ decide to continue to the agricultural college and $21 \%$ decide to leave by the engineering school gate;

- $43 \%$ of the total decide to get to the place designated by the mayor, while the remaining $10 \%$ go home.

\subsection{Scenario 3 bis results}

Scenario 3 bis is different from scenario 3 for informer, which is, in this case, the Faculty Headmaster.

Scenario 3 results are expressed in percentages compared to the total number of users and show that:

- $45 \%$ of users leave the laboratory immediately and do not wait for the specified time of evacuation;

of those who leave immediately

- $24 \%$ decide to move on foot, while the remaining $20 \%$ choose to go to the campus car park and travel by car;

- $25 \%$ decide to continue to the agricultural college and $20 \%$ decide to leave by the engineering school gate;

- $31 \%$ of the total decide to get to the place designated by the mayor, while the remaining $14 \%$ reach their homes;

of those who wait for the specified time of evacuation (55\% of the total)

- $51 \%$ of users leave the laboratory while $4 \%$ stay behind;

- $35 \%$ decide to move on foot, while the remaining $18 \%$ choose to go to the campus car park and travel by car; 
- $29 \%$ decide to continue to the agricultural college and $22 \%$ decide to leave by the engineering school gate;

- $51 \%$ of the total decide to get to the place designated by the mayor, and a percentage equal to $0 \%$ go home.

\subsection{Scenario 3 vs. 3 bis}

A comparison between the results obtained from scenarios 3 and 3 bis shows that:

- the percentage of users which immediately leaves the laboratory is the same for both scenarios $(45 \%)$;

- at reference time, for scenario 3 the percentage of users that leaves the laboratory is more high than scenario 3 bis of two percentage points $(53 \%$ vs. $51 \%$;

- the number of users who choose to go out via the agricultural college is very similar for both scenarios;

- the number of users who decide (immediately and at reference time) to reach the place designated by the informer, for scenario 3 is equal to $76 \%$, for scenario 3 bis to $82 \%$, than increasing by 8 percentage points. Then, if we consider that differences of evacuation percentage at time reference are insignificant, because very low, in this scenario the faculty headmaster is considered more reliable than the mayor.

\subsection{Scenario 4 results}

The results of scenario 4 are expressed in percentage terms compared to the total number of users. They show that:

- $76 \%$ of users leave immediately while the remaining $24 \%$ wait in the hall to obtain more reliable information;

- $61 \%$ of users move quickly to walk away from the truck, while the remaining $15 \%$ reach their cars to drive away.

\subsection{Scenario 4 bis results}

The results of scenario 4 bis are expressed in percentage terms compared to the total number of users. They show that:

- $82 \%$ of users leave immediately while the remaining $18 \%$ wait in the hall to obtain more reliable information;

- $74 \%$ of users move quickly to walk away from the truck, while the remaining $8 \%$ reach their cars to drive away.

\subsection{Scenario 4 ter results}

The results of scenario 4 ter are expressed in percentage terms compared to the total number of users. They show that: 
- $88 \%$ of users leave immediately while the remaining $24 \%$ wait in the hall to obtain more reliable information;

- $76 \%$ of users move quickly to walk away from the truck, while the remaining $12 \%$ reach their cars to drive away.

\subsection{Scenario 4 vs. Scenario 4 bis and 4 ter}

A comparison between the results obtained from scenarios 4,4 bis and 4 ter shows that:

- the percentage of people who evacuates increases of 6 percentage points from scenario 4 to 4 bis and a further 6 points from 4 bis to 4 ter, then the reliability of the informer increases passing from the unknown to the mayor up to the professor;

- the percentage of users who choose to move quickly to walk away from the truck increases of 15 percentage points from scenario 4 to 4 bis and a further 5 percentage points from scenario 4 bis to 4 ter, confirming the previous result.

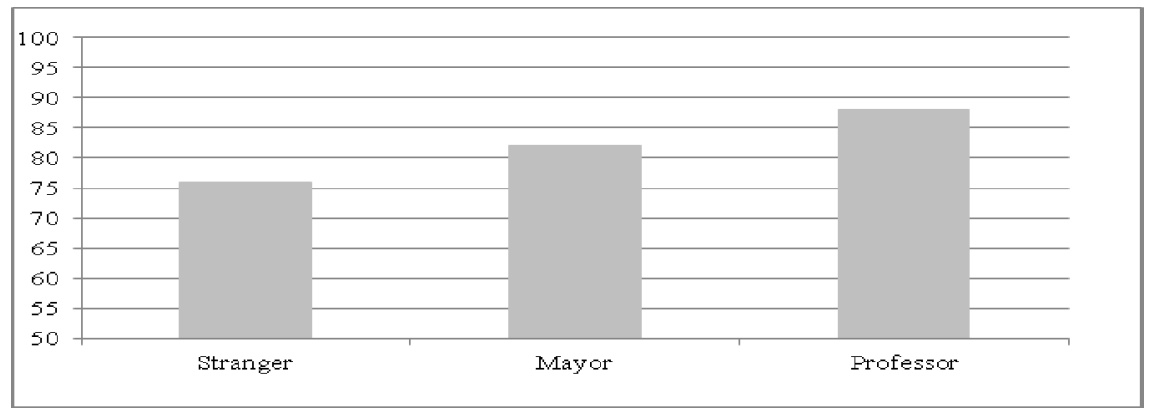

Figure 4: Evacuation percentage with respect to the informer (scenarios 4, 4 bis and 4 ter)

\subsection{Scenario 5 results}

The results of scenario 4 are expressed in percentages compared to the total number of users and show that:

- $88 \%$ of users leave the laboratory, while the remaining $12 \%$ do not trust the received information;

- $40 \%$ decide to move on foot, continuing to the agricultural college;

- $22 \%$ decide to move on foot by the engineering school gate;

- $2 \%$ decide to go to the campus car park and travel by car, continuing to the agricultural college;

- $24 \%$ decide to go to the campus car park and travel by car, by the engineering school gate;

- $61 \%$ of the total decide to get to the place designated by the stranger, while the remaining $27 \%$ go home. 


\subsection{Scenario 6 results}

The scenario 6 results are expressed in percentages compared to the total number of users and show that:

- $100 \%$ of users leave the laboratory;

- $49 \%$ decide to move on foot, continuing to the agricultural college;

- $29 \%$ decide to move on foot via the engineering school gate;

- $10 \%$ decide to go to the campus car park and travel by car, continuing to the agricultural college;

- $12 \%$ decide to go to the campus car park and travel by car, by the engineering school gate;

- $86 \%$ of total users decide to get to the place designated by the department head, while the remaining $14 \%$ go home.

\subsection{Scenario 6 vs. Scenario 5}

A comparison between the results obtained from scenarios 5 and 6 shows that:

- for scenario 6 , the percentage of users who decide to leave the workplace increases by 12 percentage points: people perceive the information on emergency conditions from the department head as being more reliable;

- the number of users who choose to go out via the agricultural college increases by 17 percentage points, as people consider the received information more reliable;

- as regards total users, for scenario 6, the number of users who decide to reach the place designated by the informer increased by 25 percentage points, confirming previous considerations.

\subsection{Scenario 5 vs. Scenario 1 and Scenario 6 vs. Scenario 2}

In scenarios 5 and 1 the informer is the same (a stranger): the differences are related to mode and path choices. In fact, in scenario 1 we propose these choices as independent (then we consider two different choices, e.g. first the car or the foot mode, and after to continue by the agricultural college or the engineering school gate); in scenario 5 these choices are considered as joint (see figure 1). These different structures of choice alternatives are finalized to analyze the formal transportation decisions.

Obtained results show that the evacuation percentage is the same, but there are differences among choices characterized by the different structure:

- the percentage of users that decide to evacuate is equal to $88 \%$ in both scenarios;

- the percentage of users that decide to move on foot is equal to $73 \%$ in scenario 1 (disaggregate alternatives), to $62 \%$ in scenario 5 (joint alternatives);

- the percentage of users that decide to move by the agricultural college is equal to $39 \%$ in scenario 1 and to $42 \%$ in scenario 5 ; 
- the percentage of users that decide to get to the place designated by the stranger is equal to $65 \%$ in scenario 1 , to $61 \%$ in scenario 5 .

Differences between scenarios 6 and 2 are similar to these of scenarios 5 and 1 . In fact, the informer is the same (the department head), but the choice structure is different (see figure 1).

Obtained results show that:

- the percentage of users that decide to evacuate is equal to $96 \%$ in scenario 2 and to $100 \%$ in scenario 6 ;

- the percentage of users that decide to move on foot is the same $(78 \%)$ for both scenarios;

- the percentage of users that decide to move by the agricultural college are equal to $55 \%$ in scenario 2 and to $59 \%$ in scenario 6 ;

- the percentage of users that decide to get to the place designated by the informer is equal to $80 \%$ in scenario 2 , to $88 \%$ in scenario 6 .

\section{Conclusion}

This work confirms the role of the informer in the user choices during evacuation conditions. We have proposed several hypothetical scenarios, considering three kinds of dangerous events, with delayed effects in time.

Our next objectives are finalized to calibrate an evacuation model, based on data obtained during SP experiments, in order to evaluate parameters of attributes and then to highlight the better choice structure (see fig. 1) to reproduce user behaviour in evacuation conditions (objectives of first level).

As in the previous experiment [23], in relation to the objectives of the second level, results point out the importance of the informer, which influences all user decisions: evacuate or not; path and destination choice.

In relation to the evacuation percentage in respect of the informer, obtained results show that higher evacuation percentages are highlighted if the informer is the department head or the professor. In fact, by comparing scenarios 1 vs. 2 and 5 vs. 6 , and then the stranger vs. the department head as informer, we highlight increases of evacuation percentages by 8 and 12 percentage points, respectively for scenarios 2 and 6 . Moreover, the percentage of user that decides to reach the place designated by the informer increases by 15 and 25 percentage points, respectively for scenarios 2 and 6. If we consider scenarios 3 vs. 3 bis, and then the mayor vs. the faculty headmaster as informer, we highlight that the evacuation percentage is similar in both scenarios, but the percentage of user that decides to reach the place designated by the informer increases by 8 percentage points in scenario 3 bis. Then the informer is considered more reliable in scenario 3 bis than in scenario 3. Finally, scenarios 4,4 bis and 4 ter confirm the role of the informer: different user behaviour is highlighted if the informer is a stranger (sc. 4, evacuation percentage equal to $76 \%$ ), a representative of the mayor (sc. 4 bis, evacuation percentage equal to 82\%) and a professor (sc. 4 ter, evacuation percentage equal to $88 \%$ ). 


\section{References}

[1] Russo F. and Chilà G., Safety of users in road evacuation: demand models. WIT Transactions on the Built Environment, Volume 96, Urban Transport XIII, Urban Transport and the Environment in the 21st century, Brebbia C. A. (ed.), WIT Press, Southampton, pp. 773-782, 2007.

[2] Russo, F., Vitetta, A., Risk evaluation in a transportation system. International Journal of Sustainable Development and Planning, 1 (2), pp. 170-191, 2006.

[3] Wilmot C.G. and Fu H., Static vs. Dynamic and Aggregate vs. Disaggregate: A Comparison between Practice and Research in Hurricane Evacuation Travel Demand Modeling. Transp. Res. Board 86th Annual Meeting, 2007.

[4] Wilmot, C.G., H. Fu, and H. Zhang. Modeling the Hurricane Evacuation Response Curve. Transportation Research Record: Journal of Transportation Research Record Board, 2022, pp. 94-102, 2007.

[5] Wilmot C.G. and Fu H., A sequential logit dynamic travel demand model for hurricane evacuation. Transp. Research Record, 1882, pp. 19-26, 2004.

[6] Cheng, G., Wilmot C.G., and Baker R.J., A destination choice model for hurricane evacuation. In Transp. Research Board Annual Meeting 2008. CD-ROM. Washington, D.C., 2008.

[7] Hasan, S., Hukkussuri, S., Murray-Tuite, P., A Behavioral Model to Understand Household Level Hurricane Evacuation Decision Making. Submitted for Publication in ASCE Journal of Transportation, 2011.

[8] Montz T., Dixit V., Wolshon B., Integration of Household Decision Making with Dynamic Transportation Modeling to Evaluate Hurricane Evacuation.http://www.homelandsecurity.org/DHSUnivSummit2011/Mont z_WhitePaper_06 May11.pdf, 2011.

[9] Russo F. and Chilà G., Safety of users in road evacuation: RP vs. SP surveys in demand analysis. WIT Transactions on the Built Environment, Volume 101, Urban Transport XIV, Urban Transport and the Environment in the 21st century, Brebbia C. A. (ed.), WIT Press, Southampton, pp. 703$713,2008$.

[10] Russo F. and Rindone C., Safety of users in road evacuation: planning internal processes and guidelines. WIT Transactions on the Built Environment, Volume 96, Urban Transport XIII, Urban Transport and the Environment in the 21st century, Brebbia C. A. (ed.), WIT Press, Southampton, pp. 825-834, 2007.

[11] Vitetta A., Quattrone A. and Polimeni A., Safety of users in road evacuation: design of path choice models for emergency vehicles. WIT Transactions on the Built Environment, Volume 96, Urban Transport XIII, Urban Transport and the Environment in the 21st century, Brebbia C. A. (ed.), WIT Press, Southampton, pp. 803-812, 2007.

[12] Vitetta A., Quattrone A. and Polimeni A., Safety of users in road evacuation: algorithms for path design of emergency vehicles. WIT Transactions on the Built Environment, Volume 101, Urban Transport XIV, 
Urban Transport and the Environment in the 21st century, Brebbia C. A. (ed.), WIT Press, Southampton, pp. 727-737, 2008.

[13] Vitetta A., Quattrone A. and Polimeni A., Safety of users in road evacuation: Modelling and DSS for paths design of emergency vehicles. WIT Transactions on Ecology and the Environment, Volume 120, Sustainable Development and Planning IV, vol.1, Brebbia C. A. (ed.), WIT Press, Southampton, pp. 485-495, 2009.

[14] Polimeni A. and Vitetta A., Dynamic vehicle routing in road evacuation: a model for route design. WIT Transactions on the Built Environment, Volume 116, Urban Transport XVII, Urban Transport and the Environment in $21^{\text {st }}$ Century, Pratelli and Brebbia C. A. (ed.), WIT Press, Southampton, pp. 627-638, 2011.

[15] Polimeni A. and Vitetta A., Dynamic vehicle routing in road evacuation: route design experimentation. WIT Transactions on the Built Environment, Volume 117, Safety and Security engineering IV, Guarascio M., Reiners G. Brebbia C. A. and Garzia F. (ed.), WIT Press, Southampton, pp. 391-402, 2011.

[16] Cascetta E. and Cantarella G.E., A day-to-day and within-day dynamic stochastic assignment model. Transp. Research A, Vol 25, pp. 277-291, 1991.

[17] Russo F. and Vitetta A., Reverse assignment: Calibrating link cost functions and updating demand from traffic counts and time measurements. Inverse Problems in Science and Engineering, Volume 19, Issue 7, pp. 921950, 2011.

[18] Vitetta A., Musolino G. and Marcianò F. A., Safety of users in road evacuation: Supply and demand-supply interaction models for users. WIT Transactions on the Built Environment, Volume 96, Urban Transport XIII, Urban Transport and the Environment in the 21st century, Brebbia C. A. (ed.), WIT Press, Southampton, pp. 783-792, 2007.

[19] Vitetta A., Musolino G. and Marcianò F. A., Safety of users in road evacuation: calibration of cost functions and simulation. WIT Transactions on the Built Environment, Volume 101, Urban Transport XIV, Urban Transport and the Environment in the 21st century, Brebbia C. A. (ed.), WIT Press, Southampton, pp. 715-725, 2008.

[20] Vitetta A., Musolino G. and Marcianò F. A., Safety of users in road evacuation: Modelling and DSS for transport supply and supply-demand interaction. WIT Transactions on Ecology and the Environment, Volume 120, Sustainable Development and Planning IV, vol.1, Brebbia C. A. (ed.), WIT Press, Southampton, pp. 475-484, 2009.

[21] Marcianò F.A., Musolino G. and Vitetta A., Within day traffic assignment and signal setting in road evacuation: a procedure with explicit path enumeration. WIT Transactions on the Built Environment, Volume 117, Safety and Security Engineering IV, Guarascio M., Reiners G. Brebbia C. A. and Garzia F. (ed.), WIT Press, Southampton, pp. 403-414, 2011.

[22] Musolino G. and Vitetta A., Short-term forecasting in road evacuation: calibration of a travel time function. WIT Transactions on the Built 
1040 The Sustainable City VII, Vol. 2

Environment, Volume 116, Urban Transport XVII, Urban Transport and the Environment in $21^{\text {st }}$ Century, Pratelli and Brebbia C. A. (ed.), WIT Press, Southampton, pp. 615-626, 2011.

[23] Russo F. and Chilà G., A statistical approach to analyse user behaviour in road evacuation. WIT Transactions on the Built Environment, Volume 117, Safety and Security engineering IV, Guarascio M., Reiners G. Brebbia C. A. and Garzia F. (ed.), WIT Press, Southampton, pp. 377-390, 2011. 